\title{
Study on the Prediction of Illuminance by Daylight in a Retractable Domed Stadium
}

\author{
Tomoko IKARI \\ Lamp \& Lighting Laboratory \\ Toshiba Lighting \& Technology Corporation \\ 4-2-15 Bakuro-cho, Chuo-ku, Osaka-shi, Osaka 541, JAPAN

\section{Shunichi FUJII} \\ Lamp \& Lighting Laboratory \\ Toshiba Lighting \& Technology Corporation \\ 1-201-1 Funakoshi-cho, Yokosuka-shi, Kanagawa 237, JAPAN \\ Paper originally published in Japanese in J. I.E.I.J. Vol. 76, No. 10, 1992
}

\begin{abstract}
A daylighting calculation method for a domed stadium is presented. Based on this method, a computer program has been developed to predict illuminance distribution by daylight in a retractable domed stadium.

Direct sunlight and skylight are considered as the daylighting sources in this program. Skylight model is based on the C.I.E. (Commission Internationale de l'Eclairage) Overcast and Clear Sky functions.

For the purpose of examine the accuracy of the prediction by the computer program, the calculations were compared with the scale model measurements. A retractable domed stadium was designed and the 1:200 scale model was made. illuminance measurements were carried out by setting the scale model under an artificial sky. The measured values were compared with the predicted values for the same conditions simulated by the computer program.

As for this stadium, the predicted values agreed well with the measured values.
\end{abstract}

\section{Introduction}

Recently, the number of the domed stadiums is increasing in Japan.

For the stadium with no roof, illuminating plan is generally designed on the conditions at night.

On the other hand, for domed stadiums such as a stadium with retractable roof or translucent roof, supplementary artificial lighting is sometimes needed depending on their geometric and photometric characteristics. Prediction of illuminance by daylight is necessary for such type of stadium to evaluate luminous environment for sports events.

As for a stadium with translucent membrane roof, there are some studies ${ }^{1,2)}$ in which photometric characteristics of membrane was investigated and daylight availability in the stadium was predicted by the newly developed computer program. The accuracy of this program was examined to prove that the program was applicable to practical situations.

As for the membrane structures with open and closed roof, a new method was developed to predict luminous environment. The method was applied to a computer program of daylight and artificial light calculation on a membrane structure. The objective of this study was to try to evaluate the appearance of the fly ball from the player's or spectator's point of view, based on the luminous contrast of the ball and its background ${ }^{33,4)}$.

As far as daylighting calculation is concerned, the modeling of the daylighting sources is important. For skylight, luminance distribution of skylight was standardized mainly by C.I.E. $5,6,7,7$.

The authors have developed a computer program to calculate illuminance by daylight in a domed stadium, such as a retractable domed stadium or a stadium with translucent membrane ${ }^{8,9,9), 10)}$. 
In this paper, the method of daylighting calculation applied for the program is described. Furthermore, the accuracy of this program was examined by the comparisons between measured values obtained from a scale model measurement under an artificial sky and calculated values by the computer program.

\section{The Method of the Calculation}

\subsection{Flow of Daylighting Calculation}

Fig. 1 illustrates the components included in the daylighting calculation. Direct sunlight and skylight passing through the opening, transmitted daylight through the roof, and interreflected light are considered.

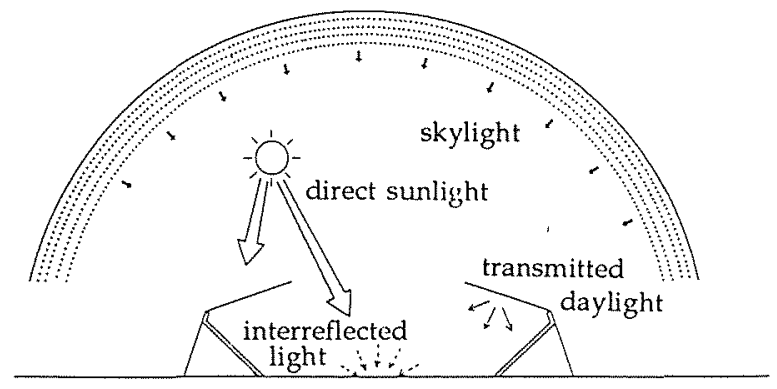

Fig. 1 Components included in the calculation program

Fig. 2 shows the flow of the daylighting calculation. The first step is geometric and photometric modeling of the interior surface of the stadium considered. The surfaces are divided into a set of small flat elements, to which reflectance and transmittance are given.

The second step is modeling of daylighting sources. The solar position is calculated from the following data: latitude and longitude of the place where a domed stadium is located, orientation of the stadium, time and date. The extraterrestrial solar illuminance and sky luminance distribution are provided based on the solar position and the sky condition.

After those steps, luminous exitance of the roof elements by transmitted daylight is calculated.

Direct illuminance from luminous exitance of the roof elements, and direct sunlight and skylight through the roof opening, are calculated. Interreflected illuminance is estimated based on the transformed formula of split-flux at the working plane.

Direct illuminance and interreflected illuminance are added up to total illuminance.

\subsection{Outline of the Daylighting Calculation}

\subsubsection{Illuminance by Direct Sunlight}

Illuminance by direct sunlight is calculated by the

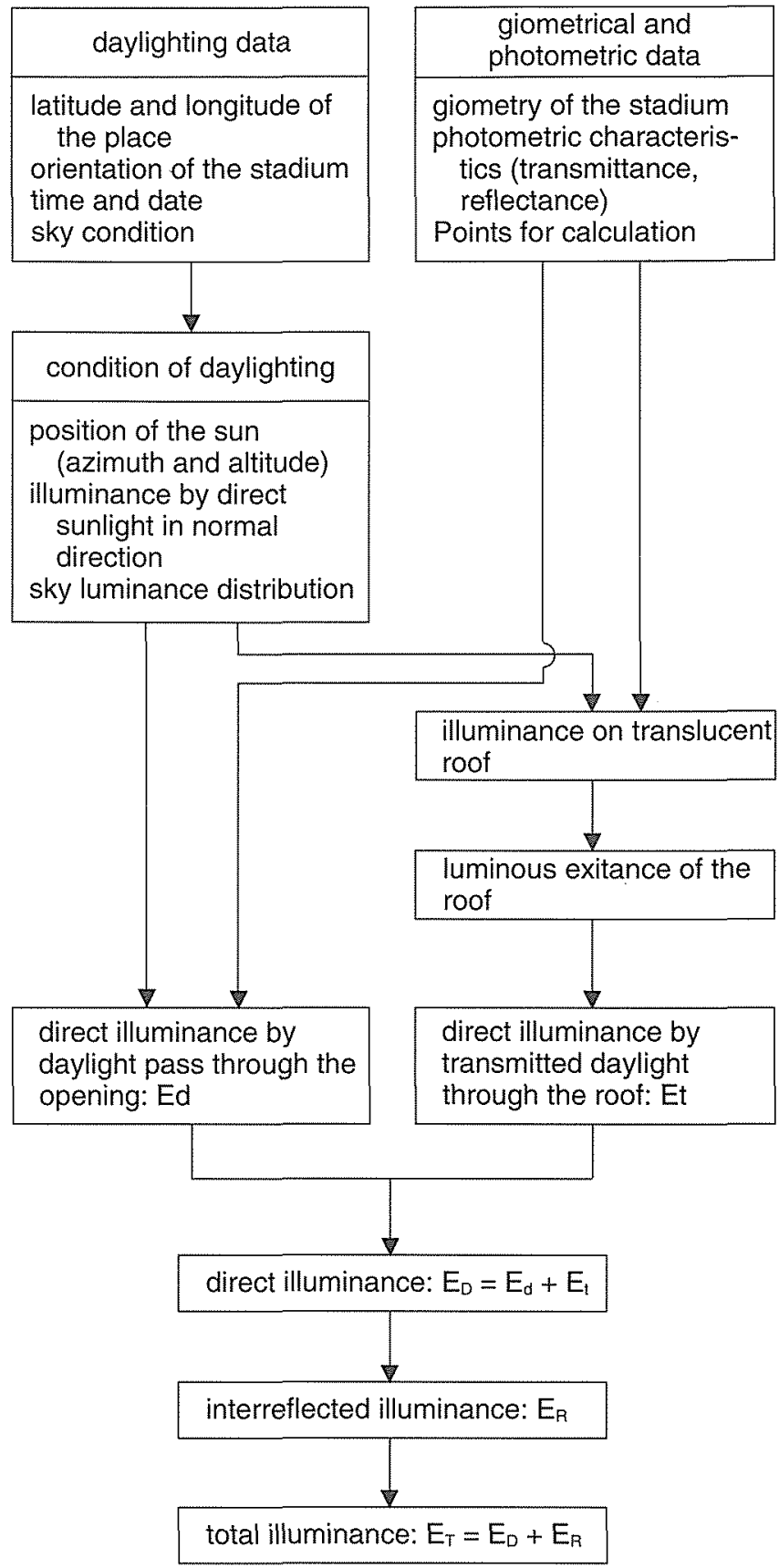

Fig. 2 Flow of the daylighting calculation

formula (1), in which the extraterrestrial solar illuminance is based on the spectral irradiance outside the atmosphere, and C.I.E. relative luminous efficiency. In this program, constant $133,800[1 x]$ is applied as the extraterrestrial solar illuminance ${ }^{11)}$.

$$
\mathrm{E}_{\mathrm{sun}}=\mathrm{E}_{\mathrm{no}} \times \tau^{\operatorname{cosec}(\mathrm{h})} \times \cos (v) \times \sigma_{\text {sun }}
$$


where

$E_{\text {sun }}$ : illuminance by direct sunlight [lx]

$E_{\text {no }}$ : extraterrestrial solar illuminance [Ix] $(=133,800 \mathrm{~lx})$

$\tau$ : transmittance of atmosphere

h : solar altitude

$v$ : the angle between direction of light incidence and normal direction of the surface in which the point being calculated is involved

$\sigma_{\text {sun }}:$ parameter of obstruction between the sun and the point being calculated if sun is seen from the point, $\sigma_{\text {sun }}$ is equal to 1 ,

if not, $\sigma_{\text {sun }}$ is equal to 0 .

\subsubsection{Illuminance by Skylight}

The sky hemisphere is assumed to be consist of small sky elements ${ }^{12}$, each of which has a uniform luminance according to the sky luminance distribution of either C.I.E. standard overcast sky expressed by the formula (2) ${ }^{5)}$ or C.I.E. standard clear sky expressed by the formula $(3)^{6)}$. The parameters in formula (2) and (3) are illustrated in Fig. 3 .

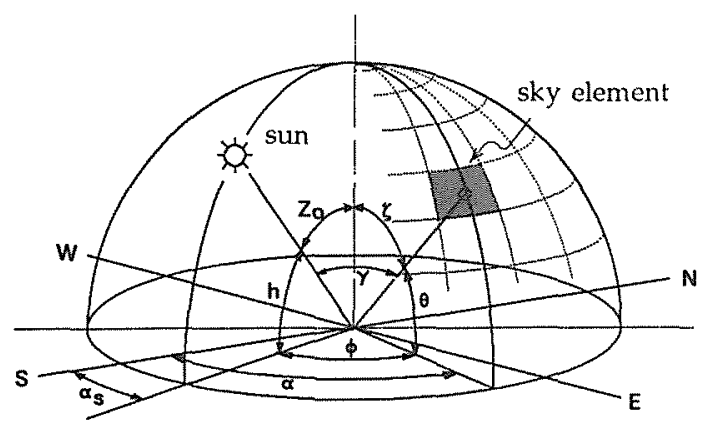

$$
\begin{aligned}
& \alpha_{s} \text { : azimuth of the sun } \\
& h \text { : altitude of the sun } \\
& \alpha \quad \text { : azimuth of the considered sky element } \\
& \theta \quad \text { : altitude of the considered sky element } \\
& Z_{0} \text { : zenithal sun angle } \\
& \zeta \text { : angular distance of the considered sky } \\
& \text { element from the zenith } \\
& \gamma \quad \text { : angular distance of the considered sky } \\
& \text { element from the sun position } \\
& \phi \quad \text { : azimuthal angle of the considered sky }
\end{aligned}
$$

Fig. 3 Parameters to express sky luminance distribution

Other sky conditions will be considered if their luminance distributions can be expressed in the format acceptable for the program.
These sky elements are treated as completely diffuse area sources.

Illuminance by skylight is calculated by the formula (4)

$$
\mathrm{L}(\zeta)=\frac{1+2 \cdot \cos \zeta}{3} \cdot \mathrm{L}_{\mathrm{zoc}}(\mathrm{h})
$$

where

$$
\begin{aligned}
\mathrm{L}_{\mathrm{zoc}}(\mathrm{h}): \text { Zenith luminance of overcast sky } \\
=15.0(\sin (\mathrm{h}))^{1.68}+0.07\left[\mathrm{kcd} / \mathrm{m}^{2}\right]
\end{aligned}
$$

$$
\mathrm{L}\left(\mathrm{Z}_{\mathrm{O}}, \zeta, \gamma\right)=\frac{\mathrm{f}(\gamma) \cdot \phi(\zeta)}{\mathrm{f}\left(\mathrm{Z}_{0}\right) \cdot \phi(0)} \cdot \mathrm{L}_{\mathrm{ZCL}}(\mathrm{h})
$$

$$
\begin{aligned}
& \text { where } \\
& f(\gamma)=0.91+10 \exp (-3 \gamma)+0.45 \cdot \cos ^{2} \gamma \\
& f\left(Z_{0}\right)=0.91+10 \exp \left(-3 Z_{0}\right)+0.45 \cdot \cos ^{2} Z_{0} \\
& \phi(\zeta)=1-\exp (-0.32 \cdot \sec \zeta) \\
& \phi(0)=0.27385 \\
& \mathrm{~L}_{\mathrm{ZCL}}(\mathrm{h}): \text { Zenith luminance of clear sky } \\
& =4.47(\tan (\mathrm{h}))^{1.13}+0.14\left[\mathrm{kcd} / \mathrm{m}^{2}\right] \\
& \mathrm{E}_{\text {sky }}=\sum\left(\pi \times \mathrm{L}_{\mathrm{i}} \times \mathrm{C}_{\mathrm{si}} \times \sigma_{\text {sky }}\right) \\
& \text { where } \\
& E_{\text {sky }} \quad \text { : illuminance by skylight [lx] } \\
& \mathrm{L}_{\mathrm{i}} \quad \text { : luminance of sky element (i) }\left[\mathrm{cd} / \mathrm{m}^{2}\right] \\
& \mathrm{C}_{\mathrm{si}} \quad \text { : configuration factor of a sky element (i) } \\
& \sigma_{\text {sky }} \text { : parameter of obstruction between the sky } \\
& \sigma_{\text {sky }} \text { is equal to } 1 \text {, } \\
& \text { if not, } \sigma_{\text {sky }} \text { is equal to } 0 \text {. } \\
& \pi \quad: 3.1415927
\end{aligned}
$$

\subsubsection{Illuminance by Transmitted Daylight}

The translucent roof elements illuminated by the daylight from outside are assumed to be the light sources, each of which has a uniform luminous exitance seen from inside of the stadium.

Daylight is considered to transmit through the translucent roof elements completely diffusively.

The luminous exitance of the roof element is calculated by the formula (5). The illuminance by the transmitted daylight is calculated by the formula (6).

$$
M_{c i}=t \times\left(E_{\text {sun }-i}+E_{s k y-i}\right)
$$




$$
\begin{aligned}
& \text { where } \\
& \mathrm{M}_{\mathrm{ci}} \text { : luminous exitance of the roof element (i) } \\
& \text { [rlx] } \\
& t \quad \text { : transmittance of the roof } \\
& \mathrm{E}_{\text {sun-i }} \text { : illuminance by direct sunlight incident on } \\
& E_{t}=\sum\left(M_{c i} \times C_{r i}\right) \\
& \mathrm{E}_{\mathrm{t}} \quad \text { : illuminance by transmitted daylight [lx] } \\
& \mathrm{C}_{\mathrm{ri}} \text { : configuration factor of a roof element (i) }
\end{aligned}
$$

\subsubsection{Interreflected illuminance}

Interreflected illuminance is averagely estimated according to the transformed formula of split-flux at the working plane ${ }^{13)}$. The ground of the stadium is considered as the working plane.

\section{Scale model Measurement and Calculation}

\subsection{Model Stadium}

Fig. 4 shows the model stadium with retractable roofs designed for the program application. The size of the model stadium was referred to that of baseball stadiums. The roofs did not have light transmitted.

The model of the stadium on a scale of 1:200 was made for the illuminance measurements.

The reflectance of interior surfaces were obtained by measuring the same sample as the model's material. The inside of the roof was light gray (reflectance $=0.66$ ), the walls were medium gray (reflectance $=0.51$ ), and the ground was green (reflectance $=0.15$ ) .

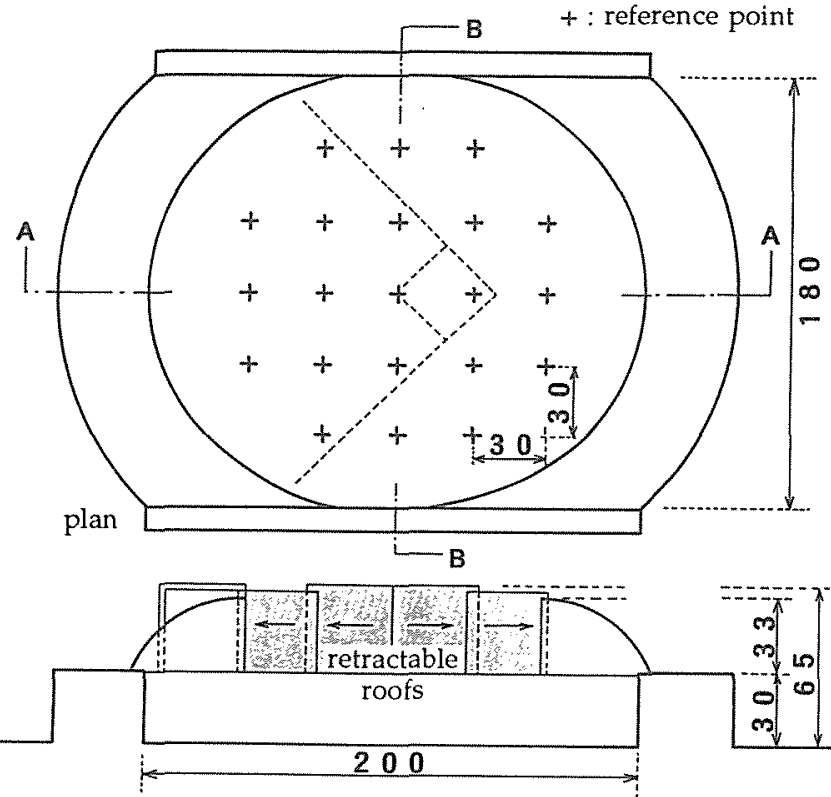

section: A-A

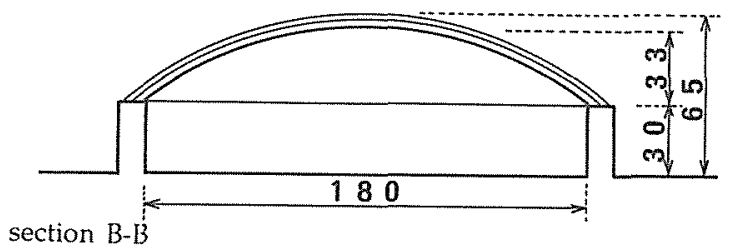

Fig. 4 Model Stadium

\subsection{Measurement}

The scale model was set under an artificial sky.

The artificial sky has hemispherical shape with 7.0 meter's diameter. The interior surface of the hemisphere is made of acrylic resin. The hemisphere is illuminated by 80040 -watt fluorescent lamps from the outside. The

Table 1 Conditions set for measurement and calculation

\begin{tabular}{c|c|c|c}
\hline Condition & $\begin{array}{c}\text { Sky luminance } \\
\text { distribution }\end{array}$ & $\begin{array}{c}\text { Condition of } \\
\text { roofd }\end{array}$ & $\begin{array}{c}\text { Horizontal illuminance from } \\
\text { unobstructed sky in } \mid x\end{array}$ \\
\hline$[1]$ & a & Full opened & 10180 \\
{$[2]$} & a & Partly opened & 10180 \\
{$[3]$} & b & Full opened & 7350 \\
{$[4]$} & b & Partly opened & 7350 \\
\hline
\end{tabular}


transmitted light through the acrylic resin creates the luminance distributions. This artificial sky can be controlled to provide certain kinds of luminance distributions. Direct sunlight can not be simulated in this artificial sky.

The measurements of illuminance were made at the ground level, at the 21 reference point on $30 \times 30$ meter's grid in full scale, on $15 \times 15$ centimeters' grid in the 1 / 200 scale model.

Two different sky conditions were set. Two different roof conditions (full opened and partly opened) were set for each of these sky conditions. So totally four conditions were set.

The luminance distribution of each sky condition was measured. The luminance distribution of "a" was approximately regarded as constant sky, while " $\mathrm{b}$ " as C.I.E. Standard Overcast sky. Fig. $\mathbf{5}$ shows luminance distribution of ' $a$ ' and Fig. 6 shows luminance distribution of 'b'.

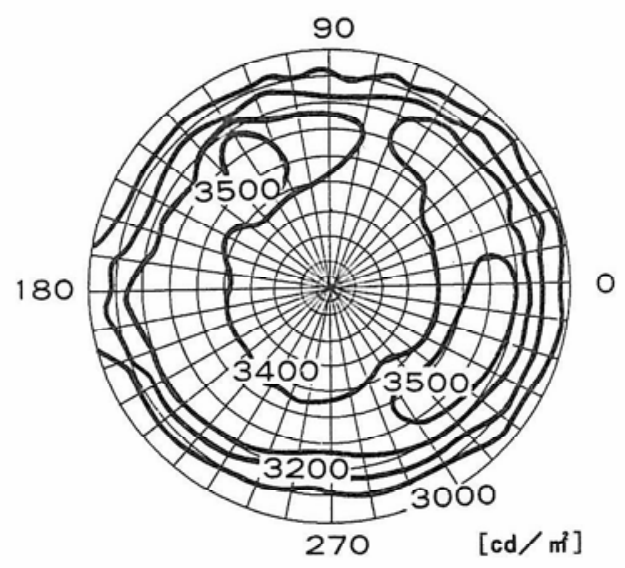

Fig. 5 Sky luminance distribution: a

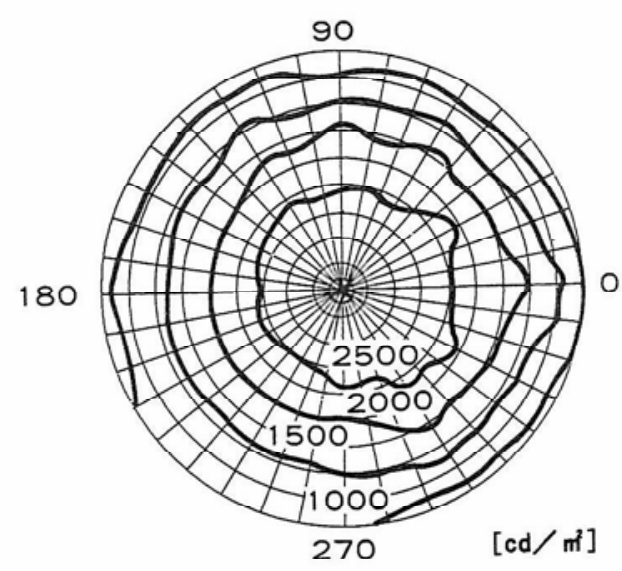

Fig. 6 Sky luminance distribution: b

The photometer used for illuminance measurement was made by Bruel \& Kjaer. Its photosensor is color-corrected

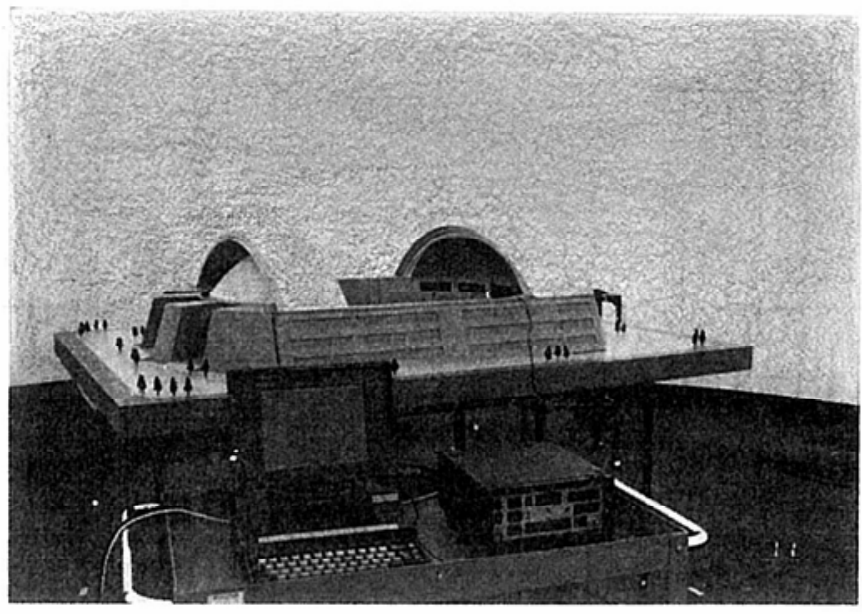

Photo 1 Scale model and illuminance measuring system

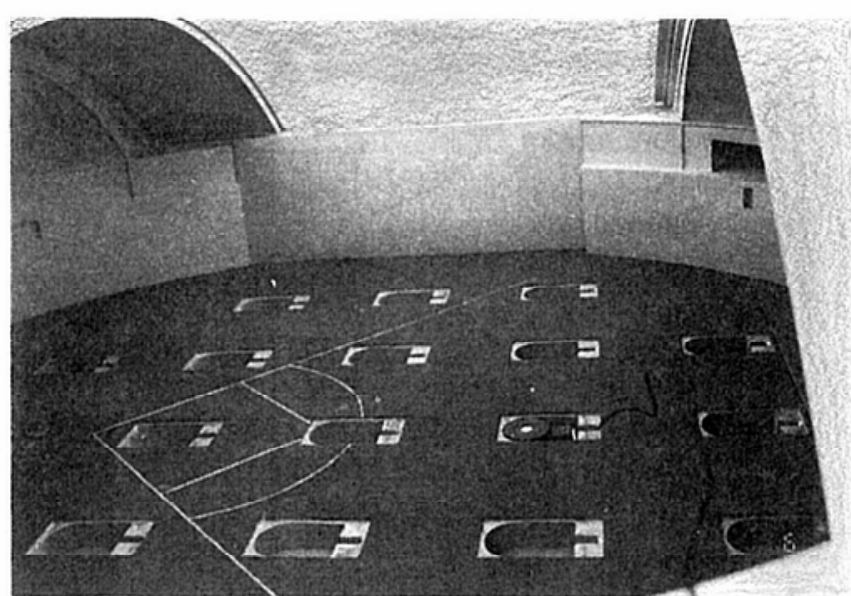

Photo 2 Illuminance measurement in the scale model

according to the C.I.E. relative luminous efficiency. This photometer has AA-grade performance standardized by JIS-C1609.

Photo. 1 shows the scale model and illuminance measuring system. Photo. 2 shows the situation of illuminance measurement in the scale model. The surface of the ground around the reference points are sunk, so that the photosensor can measure the illuminance at the ground level.

\subsection{Calculation}

The same conditions with the measurements were simulated by the computer program.

For these calculation, the measured data of sky luminance distribution was applied instead of CIE standard sky luminance distribution. 

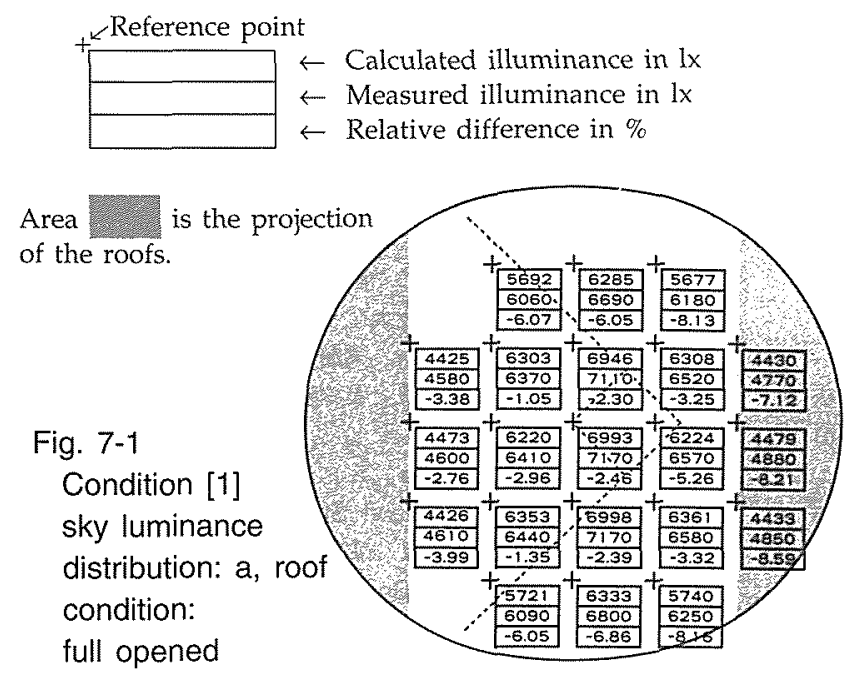

Fig. $7-2$

Condition [2] sky luminance distribution: a, roof condition: partly opened

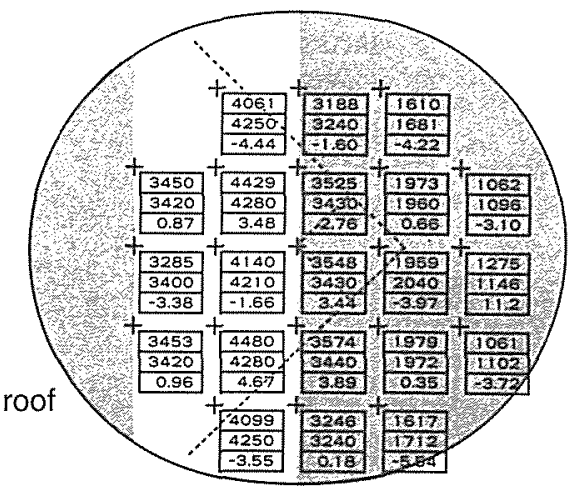

Fig. 7-3 Condition [3] sky luminance distribution: $b$, roof condition: full opened

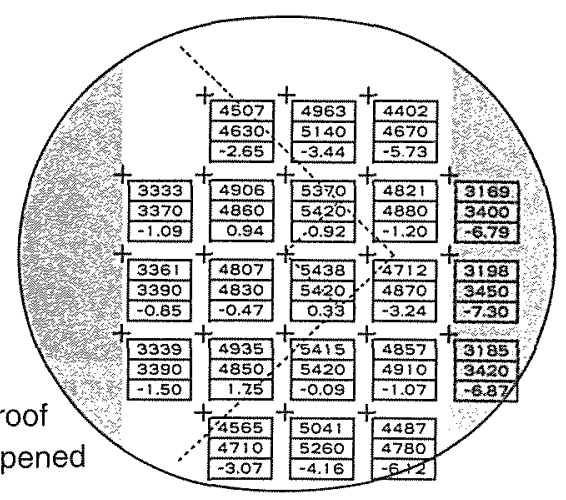

Fig. 7-4 Condition [4] sky luminance distribution: $b$, roof condition: partly opened

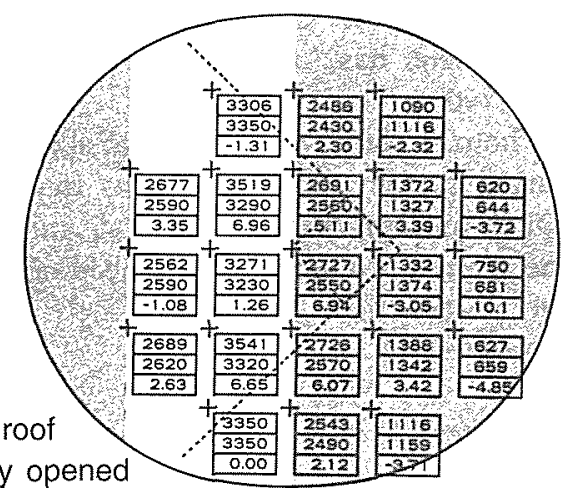

Fig. 7-1 to Fig. 7-4 Calculated illuminance and measured illuminance, and relative difference between them at each reference point

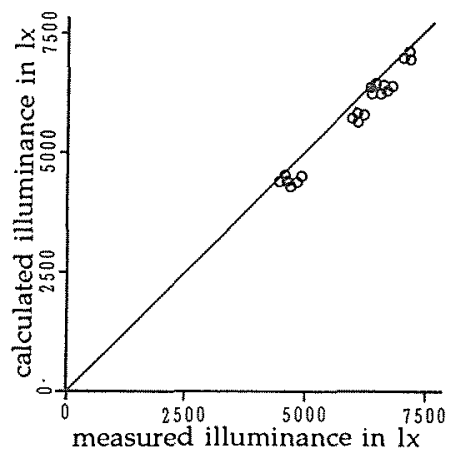

Fig. 8-1 Condition [1] Sky luminance distribution: a, roof condition: full opened

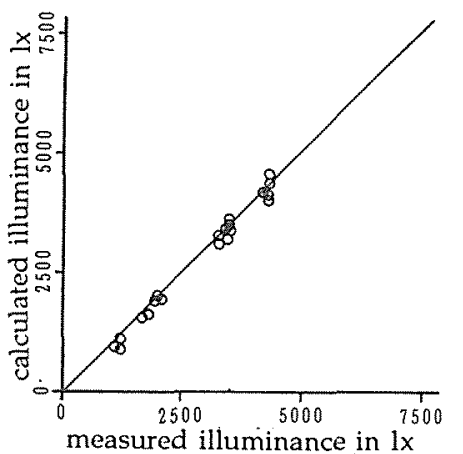

Fig. 8-2 Condition [2] Sky luminance distribution: a, roof condition: partly opened

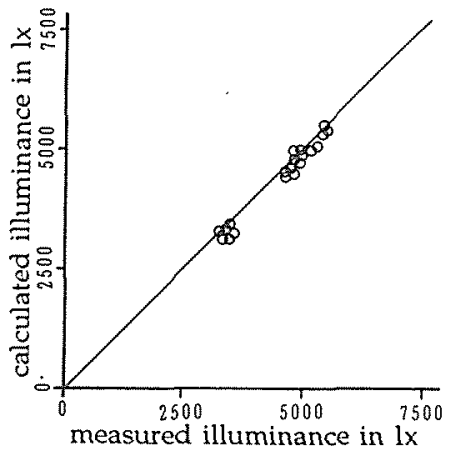

Fig. 8-3 Condition [3] Sky luminance distribution: b, roof condition: full opened

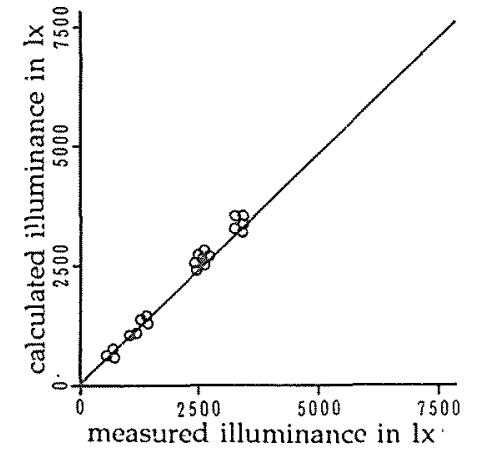

Fig. 8-4 Condition [4] Sky luminance distribution: b, roof condition: partly opened

Fig. 8-1 to Fig. 8-4 Relation between calculated illuminance and measured illuminance 
3.4 Comparison between measurement and calculation

The measured illuminance at each point was compared with the calculated one by the relative difference obtained by the formula (5)

\author{
(Relative Difference) $=$ \\ (Calculated Value - Measured Value) / \\ (Measured Value)
}

\subsection{Results of Comparison}

Fig. 7-1, 7-2, 7-3 and 7-4 show the calculated illuminance, measured illuminance and relative difference at each reference point, for each of four conditions respectively.

Fig. 8-1, 8-2, 8-3 and 8-4 illustrate the relation between calculated illuminance and measured illuminance for each of four conditions respectively. Averaged values of measurements, and of calculations are shown in illuminance and in daylight factor in Table 2. Table 2 also shows the maximum and minimum values of calculated and measured values and relative difference.

The illuminance at the 21 points were generally well predicted for all the four conditions. The average of absolute values of relative difference was within $5.0 \%$, with maximum of $11.3 \%$.

\section{Discussion of Results}

According to Fig. 7, Fig. 8 and Table 2, the calculated values are generally well agreed to the measured values.

In condition [1] and [3], calculated values are smaller than the measured values, especially in the perimeter of the ground. One of the reason is expected that interreflected component is calculated uniformly, and is estimated less in this area, where the interreflected illuminance from the walls is considered to be larger than that in the other area. There is not such a clear tendency observed in condition [2] or [4] as in condition [1] and [3]

As for the conditions set for this test, the ratio of interreflected illuminance to the averaged total illuminance is so small (under $5.0 \%$ ) that the approximation of interreflected illuminance did not have much effect on the total illuminance.

\section{Conclusion}

The outline of the daylighting calculation method for a domed stadium is presented, based on which a computer program was developed.

In order to examine the accuracy of this program, calculations were compared with scale model measurements. Illuminance measurements were carried out by setting a scale model of a retractable domed stadium under an artificial sky. The measured illuminance was compared with the calculated illuminance for the same conditions simulated by the program.

As for this application, the predicted values agreed well with measured values, though the condition of this application had some limitations, i.e. the roofs of the model stadium were retractable but not translucent, or direct sunlight was eliminated from measurements and calculations.

We are trying to continue experiments on the accuracy of this computer program by applying it to the conditions which we have not examined yet.

Table 2 Comparison between calculated illuminance and measured illuminance

\begin{tabular}{|c|c|c|c|c|c|c|c|c|c|}
\hline \multirow{3}{*}{ Condition } & \multirow{2}{*}{\multicolumn{2}{|c|}{$\frac{\text { Meaured value }}{\text { Total }}$}} & \multicolumn{4}{|c|}{ Calculated value } & \multirow{3}{*}{$\begin{array}{l}\text { Ratio of inter-. } \\
\text { reflected illum. } \\
\text { to total illum. }\end{array}$} & \multirow{2}{*}{\multicolumn{2}{|c|}{$\begin{array}{c}\text { Relative } \\
\text { difference [\%] }\end{array}$}} \\
\hline & & & \multicolumn{2}{|c|}{ Total } & \multicolumn{2}{|c|}{ Interreflected } & & & \\
\hline & lllum. & d.f. & Illum. & d.f. & lllum. & d.f. & & $\max$ & $\min$. \\
\hline$[1]$ & 6033 & 59.3 & 5753 & 56.5 & 163 & 1.60 & 2.83 & -1.05 & -8.59 \\
\hline [2] & 2905 & 28.5 & 2905 & 28.5 & 130 & 1.28 & 4.48 & +11.2 & -5.54 \\
\hline [3] & 4527 & 61.6 & 4420 & 60.1 & 125 & 1.70 & 2.83 & +1.75 & -7.30 \\
\hline$[4]$ & 2154 & 29.3 & 2209 & 30.1 & 98 & 1.33 & 4.44 & +10.1 & -4.85 \\
\hline
\end{tabular}

illum. : illuminance in $\mathrm{Ix}$

d.f. : daylight factor [\%]

Total illum. or d.f. in each condition is the averaged value at 21 reference points. 


\section{Acknowledgements}

The authors wish to thank Professor Kunio MATSUURA at Setsunan University and Professor Toshimoto MTYATA at Chiba University for their helpful advice and aid.

\section{References}

(1) IKAWA N., TANAKA Y.: A study on daylight availability of fabric structure (part 1), Summaries of technical papers of annual meeting A.I.J., pp. 479480 (1985)

(2) IKAWA N., TANAKA Y.: A study on daylight availability of fabric structure (part 2), Summaries of technical papers of annual meeting A.I.J., pp. 481482 (1985)

(3) MATSUURA K., et al: Daylight calculation and prediction of luminous environment for the membrane structures with open and shut roof (part 1), Research report of Kinki branch of A.I.J., pp. 37-40 (1990)

(4) MATSUURA K., et al: Daylight calculation and prediction of luminous environment for the membrane structures with open and shut roof (part 2),
Research report of Kinki branch of A.I.J., pp. 41-44 (1990)

(5) C.I.E. Proc. 13th Session (1955), vol. 2, part 3-2

(6) C.I.E. Standardization of Luminance Distribution on Clear Sky, C.I.E. Pub. No. 22 (TC-4.2) (1973)

(7) NAKAMURA H.: Report of the series of study on the lighting calculation method aming at efficient utilization of daylight (1988)

(8) IKARI T., KODAIRA S.: Calculation of illuminance distribution in a membrane structure including daylight component, Proc. of 1989 annual conference of the Illum. Engng. Inst. Jpn., pp. 58-59 (1989)

(9) IKARI T., FUJII S.: Prediction of daylight illuminance in a domed stadium, Proc. of 1989 annual conference of the Illum. Engng. Inst. Jpn., p. 94 (1989)

(10) IKARI T., KODAIRA S.: A Daylighting Calculation Program for a Domed Stadium, C.I.E. Proc. 22th Session Div. 3 (1991), pp. 126-127

(11) C.I.E.: Guide on Daylighting of Building Interiors, Draft (1991)

(12) TREGENZA P.R.: Subdivision of the sky hemisphere for luminance measurements, Lighting Res. Technol. 19 (1987), pp. 13-14

(13) MATSUURA K.: Architectural Lighting, pp. 116118 (1971) 